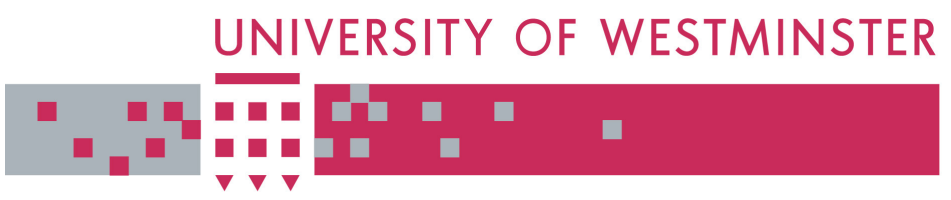

\title{
WestminsterResearch
}

http://www.wmin.ac.uk/westminsterresearch

\section{Go with the flow or seize control? Interaction principles that make games enjoyable.}

\section{Cathy Grundy ${ }^{1}$ Andrew Blake ${ }^{2}$}

${ }^{1}$ Cavendish School of Computer Science, University of Westminster

${ }^{2}$ School of Computing, Mathematical \& Information Sciences, University of Brighton

Copyright (C) [2005] IEEE. Reprinted from 27th International Conference on Information Technology Interfaces, 2005, pp. 277-282.

This material is posted here with permission of the IEEE. Such permission of the IEEE does not in any way imply IEEE endorsement of any of the University of Westminster's products or services. Internal or personal use of this material is permitted. However, permission to reprint/republish this material for advertising or promotional purposes or for creating new collective works for resale or redistribution must be obtained from the IEEE by writing to pubs-permissions@ieee.org. By choosing to view this document, you agree to all provisions of the copyright laws protecting it.

The WestminsterResearch online digital archive at the University of Westminster aims to make the research output of the University available to a wider audience. Copyright and Moral Rights remain with the authors and/or copyright owners. Users are permitted to download and/or print one copy for non-commercial private study or research. Further distribution and any use of material from within this archive for profit-making enterprises or for commercial gain is strictly forbidden.

Whilst further distribution of specific materials from within this archive is forbidden, you may freely distribute the URL of WestminsterResearch. (http://www.wmin.ac.uk/westminsterresearch).

In case of abuse or copyright appearing without permission e-mail wattsn@wmin.ac.uk. 


\title{
Go with the Flow or Seize Control? Interaction Principles that Make Games Enjoyable
}

\author{
Catherine Grundy, \\ Senior Lecturer, School of Computer Science, \\ University of Westminster, 115 New Cavendish St., London,W1M8JS \\ grundyc1@wmin.ac.uk \\ Andrew Blake \\ Senior Lecturer, School of Computing, Mathematical and Information Sciences, \\ University of Brighton, The Watts Building, Lewes Rd, Brighton. BN 24GJ \\ a.1.blake@brighton.ac.uk
}

\begin{abstract}
A series of design principles relevant to creating graphics for games interfaces were interpreted from the work of leading interaction experts. Students studying for an MSc in Computer Games Graphics were asked to explore how the principles might improve enjoyment of a game. The graduates of the course consider visual themes and their layout; they were asked to develop graphical designs to test ideas and evaluate them within the group. The purpose of the activity was to consider how emotional responses might be improved, during game play, beyond levels of satisfaction usually asociated with usability
\end{abstract}

Keywords. Computer Games, Fun, Interaction Principles, Graphics, Cognitive Model, Engagement, Flow, Experience based design.

\section{Introduction}

To design successful game play, meeting practical and emotional needs, we need to optimise communication between the user and the technology. To do this graphic developers need to consider how design and layout affects our interactions and how this consequently influences our experience. Interaction principles might seem a restrictive or unnecessary starting point for creating something as potentially exciting and entertaining as game graphics. However, to develop a design without first studying such principles, especially those that consider how our brains percolate ideas could be unprofitable.

The work of many interaction experts has emphasised 'task oriented' approaches often associated with software development. This is typified by work of Johnson [10]. Though these approaches are appropriate for work based developments, they often do not go far enough when it comes to interfaces which are intended to entice and please the user. There has been much discussion that approaches to "usability" are not enough and the qualitative aspects of design should come to the fore [Sanders, 18] For games development this is a priority. Overbeeke et al. devoted a paper to the subject 'Beauty in Usability: Forget about Ease of Use!' [16] which was devoted to the subject of making interaction a more fun and 'beautiful' experience. It may first appear that usability issues are being disregarded, but in fact the article goes on to describe a series of usability based approaches, which should be considered from a different angle. Many usability studies have focussed on cognitive skills. Overbeeke et al. emphasise that it is equally important to include emotional skills. If we concentrate on how we feel about an interface, then perhaps it will be more 'usable'.

Shigeru Miyamoto (the creator of Mario and Zelda) designs his games around a series of specific emotional experiences. The importance of appealing to the emotions and introducing an ideal experience is well recognised by games professionals, but thus far the full potential of games has not been recognised. According to Sykes [21] in his paper 'Affective Gaming', the immaturity of the games industry means that it is relatively poor at accessing our feelings in an intended manner. Though games are a visual medium, well understood techniques for eliciting emotions from film and other media are not transferable. We must understand a great deal more about the role of the graphical interface during interaction in forming our experience of the play.

It is useful therefore to turn to expert advice about interaction. One of the initial challenges for research in this area was to collate and review the goals set out by Interaction Design gurus, 
usually directed at practical understanding and consider how they might influence emotional factors for games. The project focussed on how ideas could be interpreted for creative development of games graphics. Recently experts have turned their minds to 'fun' aspects of computing, including Nielsen and Karat [16] this is clearly a developing area of research.

\section{Method}

Interaction principles were reviewed to evaluate their usefulness for design of the graphical aspects of a game, against both practial and more emotional requirements. Each principle was considered in terms of which emotions might be influenced. This helped to consider their significance to enjoyment and being immersed in the game. Design methods for generating ideas according to these principles were also considered, using techniques for creating visual designs during research at the University of Westminster and also through an industrial project with a leading London innovations consultancy. To review their success, students subsequently applied the principles through their work and designed game elements accordingly. There were 8 students the first year and 9 the following, representing an $\mathrm{MSc}$ in Computer Games graphics.

\section{Interaction Principles}

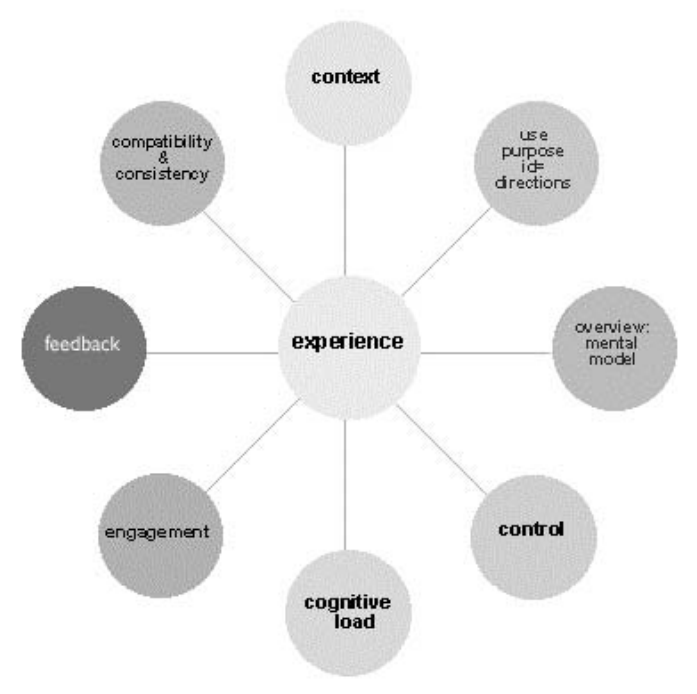

Fig 1: Principles for Designing Interaction to improve the game experience

The following guidelines are influenced by the work of leading theorists in defining goals for the design of interfaces, together with practical experience through research at the University of Westminster and PDD Ltd, a leading innovations consultancy. The common themes identified were interpreted to create principles suitable for game development.

\subsection{Design Principle1: Understand the Context prior to designing.}

Leading interaction specialists, including Preece, [17] have identified that understanding the context before developing an interface is vitally important. Emotional and usability criteria for design need to be carefully based on a review of the context. This points to the importance of user research and including the user as a stakeholder in the whole design process. Three factors were identified at Westminster which would help to outline the required experience for contextual study, 'Use, Purpose and Identity' Though they are interrelated it is helpful to categorise desired attributes for study. Most subsequent design principles described are influenced by the Contextual understanding.

Use: Can users navigate through an interface simply and effectively and see what they are required to do? Will they learn it easily and does the interface generally meet indicators of 'usability'. These are usually the factors that fulfil Tiger's [21] definition of 'Psycho-pleasure' , also explored by Jordan [9] for Product Design ensuring that the user feels a sense of achievement, is satisfied with what they have done and gains a sense of individual pride in learning or doing something important to them. They may also gain a sense of freedom, due to the efficiency of completing the task and moving on to something else. Addressing these factors will avoid pain, frustration, and negative annoyances at the interface.

Purpose: Why might people want to play the game and what motivates people about it? What are the goals and are they visible. This also covers the reasons why an onlooker might want to continue to play. The purpose will have a strong influence on the way the usability and emotional criteria for design are identified. No matter how straightforward a game interface is to use, it won't be of interest unless the design is created to encourage the user. It was agreed in discussions that having a sense of purpose towards any life experience makes a dramatic 
difference to our enjoyment of it. When applied to a game, it will affect motivation, enjoyment, fun, level of commitment and degree of effort besides enhancing the feelings of achievement .

Identity: Will users relate to the nature and style of the game? This defines empathy between a game and its observer on a visual and practical level. It should look like something that particular people will identify with and should have characteristics in keeping with a particular user group. Unless a design sends out the right signals to the user, it will be overlooked. It has to have the correct visual language to communicate with them on a semantic level. It should also respond in an appropriate way. Emotional factors discussed included an overall increased engagement and enthusiasm for using the interface.

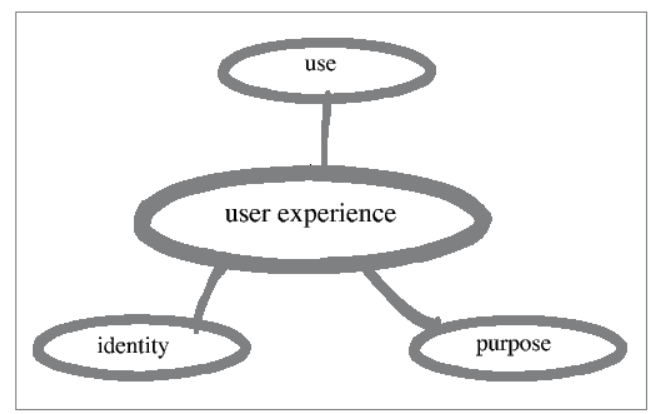

Fig 2. Use purpose and identity as components of the game experience.

\section{2 Design Principle 2: Provide the user with a clear overview.}

For any interface, the user will form an initial mental picture of how it works and get a feeling about the content it represents. Ideally we would wish a player to know where to start with a game and also for them to feel an initial engagement with it. How can the tasks, structure and content be represented in order to create a useful picture in the mind of the observer that helps them understand and appreciate the experience? Phil Johnson-Laird and Ruth Byrne [10] are among many researchers expounding the mental model theory. They assert that people form 'mental models which are representations in the mind of real or imaginary situations.' Careful consideration of the conceptual model created for a game interface can influence players mental picture in a beneficial way.

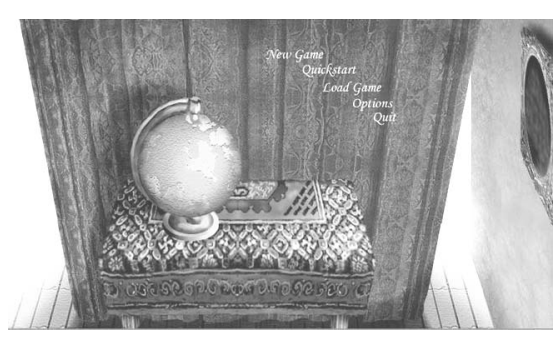

Fig 2: Menu system for a game designed by University of Westminster student Adam

Schofield. It uses the metaphor of a room and familiar objects to make it simpler to understand the sequence of choices required.

It was noted that, with an ideal cognitive model, feelings of confidence and security might be improved alongside most of the emotional factors relating to usabilty like satisfaction with a job done, contentment and feelings of empowerment. It was also envisaged that, with a creative and metaphorical style of cognitive model the whole interface could be made more fun and elicit excitement.

\subsection{Design principle3: Optimize the Cognitive Load}

Psychologists have proved that there is an optimum Cognitive Load for a human being to maintain the right level of interaction with an interface. If there is too much going on, we are likely to become confused and bewildered. If there is too little, we become bored and our attention wanders. This is a fundamental principle introduced in standard ergonomic textbooks. [Grandjean 8] Cooper and Reimans work [2], discusses interface design by analogy with human interaction. Here we might make a comparison with someone who talks too much or gives us more information than we need compared with a character who is not forthcoming. This particular approach has an almost direct manifestation for adventure or role play game design where interaction with virtual characters is important.

It was discussed that effort is almost certainly connected to the amount of stimulation felt during a game. This varies on a scale from frustration and boredom at the lower end of mental load, to excitement through to panic as the level increases. The cognitive load was considered to affect our ability to cope and thus whether we feel confident and in control of the situation. The load is likely to affect feelings of 
satisfaction associated with usability and psychopleasures of optimizing efficiency.

\subsection{Design Principle 4: Who takes control?}

How much control should the user have over what happens, and how far should this be guided by the technology? A factor discussed by Jordan [9], and Norman [15] (in the form of 'constraints'). When is it necessary to design an interface that constrains the user to avoid making mistakes, and when is it possible to allow greater flexibility? Only a proper study of context can decide these issues. Understanding who the game is for ie reviewing its 'Identity' will dicate the level of control, A way of avoiding a high cognitive load is for the technology inside of an interface to take more of the decision making away from us, thus also helping to avoid mistakes.

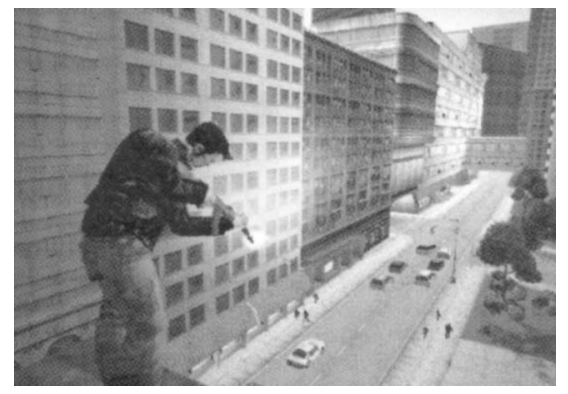

Fig 3: Screen shot from Grand Theft Auto.

For a game interface, one might imagine it is ideal to let the user take a larger share of the interaction, since the player controlling game elements forms a large part of the entertainent. However it is important that the game does not allow players to make moves that are in conflict with the basic game programming and to remove too many decisions that would interfere with enjoyment. Grand Theft Auto is an example of a game that allows players to wander off the usual beaten track of direct game play and create their own script for activities. Many enjoy this flexibility. However, this is confusing for others, perhaps new game consumers, who might prefer to quickly work out the purpose and goals of a game.

Control was thought to influence feelings of empowerment or restriction, freedom and confidence.

\subsection{Design principle 5: Go with the flow.}

Intitial attraction to the material presented was deemed important and subsequently so was maintaining engagement. Beyond an overview of what is possible for an interface and how to proceed, it is also ideal to maintain a feeling of being guided through parts of the process. Alan Cooper et al. [2] suggest in their textbook "About Face 2 " that "Flow" is a factor that strongly influences our experiences in most situations. "When people are able to concentrate wholeheartedly on an activity, they lose awareness of peripheral problems and distractions" The notion of Flow is further defined by Mihaly Csikszentmihalhi in "Flow : The Psychology of Optimal Experience [3] They describe Flow as a "condition of deep, nearly meditative involvement". Feelings of freedom and relaxation were associated with absorbtion and escapism during engagement.

\subsection{Design Principle 6: Be explicit (where appropriate).}

Most design gurus agreed that the available function and uses of an interface should be made 'visible'; that it should be explicit through its form and meaning. If we broaden this requirement beyond usability needs, the purpose and identity should also be expressed clearly within the design. In the human analogy introduced by Cooper [2] this principle in usability terms is similar to a person being friendly, helpful and forthcoming. However sometimes elusive people are more fascinating! An 'elusive' interface that attempts to be intriguing to a user may wish to keep some of its nature hidden in the initial stages of use. Again, the context is needed to guide just how exlicit it should be.

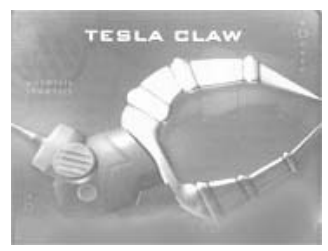

Fig 4: Affordant design of an in game object giving explicit direction the the player.

Emotional Factors: Our reaction to an explicit interface will likely correspond with how we might react to a friendly person, again the context is all important. Explicitness can directly 
affect the usability and associated feelings, however sometimes an interface can appear to be labouring a point or being too patronising in its approach. Comparing web sites designed for children, with those for adults, often the navigation and nature of the site in general are far more expressive and affordant, the level of affordance will directly affect the aesthetics and identity of the presentation.

\subsection{Design principle 7: Give useful Feedback}

Donald Norman [15] and most HCI experts stress the importance of feedback about what has been achieved or where a user is within an interface. This represents responsiveness and the essence of a 'conversation' about what actions are performed, it is a specific case of interaction. However the feedback must be unobtrusive; we might wish the interface to be alert to our actions, but also not interrupt us in what we are doing. Alarm signals for games are a case of feedback where thre is a need to draw attention (like the failing health of a games character). Again, if we analyse the human qualities of the interface and its level of 'consideration' in accordance with Cooper et. $\mathrm{Al}$, this can be understood in terms of a helpful polite, and friendly person. Our feelings will likely mirror our reaction to such a human interaction.

\subsection{Design principle 8: Only allow pleasant surprises}

Normally an interface should respond in the way we expect it to; indeed this is one of the fundamental lessons that usability experts will cover under the guise of good 'compatibility ' between our expectations and what actually happens when we perform an action. This is discussed by Jordan and Norman, but is also a standard feature of most Ergonomic textbooks (Grandjean). Compatibility describes situations where our expectations are based on what might naturally be assumed in circumstances where we may be 'encountering' an interaction for the first time, it does not necessarily describe instances where expectations are formed from memory.

Keeping designs consistent can be considered as a subset of compatibility with expectations. This can be directly interpreted as keeping working models, navigation and screen layouts consistent throughout a design or more broadly keeping the whole interface consistent with our likely mental model of it. It is mentioned by Jordan, Johnson, Preece et al.

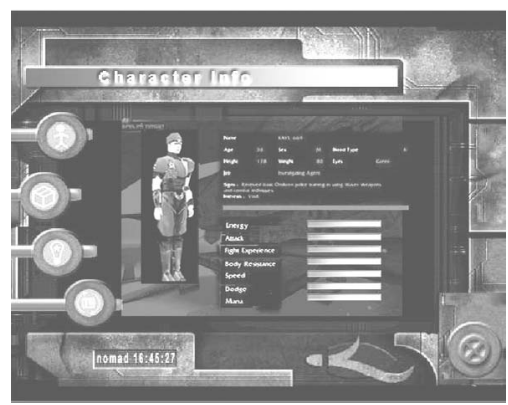

Fig 5: Example of interface redesigned to be more compatible with expectations, created by $\mathrm{Vi}$ Bang, Westminster Student. The buttons were designed to be intuitively connected with their function and remained in the same place on consecutive screens.

High compatibility with our expectations was considered to affect our sense of comfort and security, it is also helpful to our sense of orientation 'where we are' with something both spatially and more broadly. However, 'pleasant ' surprises are considered an important aspect of the fun and enjoyment possible for the system. If something is not where we expect it to be, we might feel a sense of loss, certainly one of confusion and annoyance.

\section{Conclusion}

The project represents a broad sweep through ideas about interaction and their application to a range of games and different genres. This is appropriate to an early stage of research in the subject and allows subsequent focus on interesting developments. Feedback from the student group indicated that the design principles provided a useful and interesting starting point to attempt to improve game enjoyment. It seemed that they were able to create redesigns of game elements which were more emotionally appealing to each other using ideas that were introduced. The principles themselves have been better explored and expanded upon through student work and will continue to do so with each subsequent cohort.

The issues under study are largely unquantifiable and subjective in their nature, making it difficult to uncover evidence for their 
validity that is anything other than anecdotal. However, the improvements noted by a group of this size are not entirely unworthy of note. Anonymous tests could be added in future to give more reliable feedback. It would also be ideal to present the principles to external bodies, including games companies for alternative opinion .

For each game under study, it is difficult to predict which principles will be most appropriate and which will be irrelevant. Therefore it is difficult to single out principles individually for review. For some a clear overview and novel conceptual model for starting the process of play will be important. For others, an initial air of mystery will be preferred, with more emphasis on improving the flow of activities through improving the level of engagement. Additionally many of the principles are interdependent, so narrowing down the study by focussing on each would be to miss the point. The set of principles works best as an iterative check list of issues to be remembered and emphasised through design. To make a more controlled study it might be best to consider particular game genre or even a specific game and review the Interaction 'check list' against it.

\section{References}

[1] Alben, L. Quality of Experience: Defining the criteria for Effective Interaction design, Interactions, 3.3, issue may/june, p 11, 1996

[2] Cooper, Alan, Reiman, Robert. About Face: The Essentials of Interaction Design, Indiana, USA, Wiley publishing, 2003

[3] Csikszentmihalhi, Mihaly. Flow: The psychology of optimal experience, Harper Collins, 1991

[4] Fincher, Sally, Markopulos, P,(Ed.), Moor, D(Ed.) In People and Computers: XVIII: Design for Life proceedings of HCI 2004Springer Verlag publishers, 2004

[5] Forlizzi, Jodi, Towards a Framework of Interaction and Experience As It Relates to Product Design, 2002.

http://goodgestreet.com/experience/home.ht $\underline{\mathrm{ml}},[21 / 8 / 04]$.

[6] Frascara, Jorge, Cognition, Emotion and other inescapable aspects of human experience, 2003, www.id.iit.edu/visiblelanguage/Feature Arti cles/Frascara_CognitionEmotion/index.html [16.10.03]
[7] Garrett, Jesse James, The Elements of User Experience , US, New Riders, 2003

[8] Grandjean, KHE, Fitting the task to the human,London, Ta ylor and Francis, 1999 Grand Theft Auto III, DMA Design., Rock star games, 2001

[9] Jordan, P, Pleasure in Product Use: beyond usability, Contemporary Ergonomics, 2000

[10] Johnson, P. HCI: psychology, task analysis and software engineering. Maidenhead, McGraw-Hill, 1992.

Johnson-Laird, P.N. Mental Models: Towards a Cognitive Science of Language, Inference, and Consciousness. Cambridge: Cambridge University Press; Cambridge, MA: Harvard University Press. [1983)]

[11] Lakoff, G. Johnson, ,M..Metaphors we live by, Chicago, Uni of Chicago Press, 1982

[12]LewisC.S, The four loves, London, Fount.

[13]Lionhead games, www.lionhead.com, [30.10.03]

[14] Nielsen, Jakob, Designing Web Usability: The practice of simplicity, Wiley, 2000.

[15]Norman, Donald, Emotional Design and why we love (or hate) Everyday Things, New York, Basic Books, 2004.

[16] Overbeeke, K. Beauty in Usability: Forget about Ease of Use!

[17] Overbeeke, K. Blythe, MA. Funology from usability to enjoyment. London Kluwer Academic publishers, 2003.

[18] Preece, Jenny, Rogers, Y,Sharp, H. Interaction Design: beyond Human Computer Interaction, USA, Wiley, 2002

[19] Sanders, E, Postdesign and Participatory Culture, Useful and Critical: the position of Research in Design, University of Art and Design (Helsinki), 1999

[20] Scheiderman, Ben. Designing the User Interface: I,Addison Wesley, 1998

[21] Sykes, Jonathan. Affective Gaming. www.igda.org/columns/ivorytower/ivory_Ja n04.php

[21] Tiger, LionelThe Pursuit of Pleasure , Boston, Brown and Co, 1992

[22] Tognazzini, Bruce. First Principles (of interface design), 2003 www.asktog.com/ basics/firstPrinciples.html [6.10.04] 